\title{
Impact of Using the Technology of Deep Placement of Super Granulated Urea in Rice Cultivation in the Senegal River Valley and the Anambé Basin
}

\author{
Amadou Abdoulaye Fall* \\ Senegalese Institute of Agricultural Research (ISRA), USA
}

Submission: February 05, 2019, Published: February 14, 2019

"Corresponding author: Amadou Abdoulaye Fall, Senegalese Institute of Agricultural Research (ISRA), CRA de Saint-Louis, Test Garden Sor, SaintLouis, Senegal, USA.

\begin{abstract}
In Senegal River Valley (VFS) and the Anambé basin, rice is mostly marketed requiring a high consumption of fertilizers applied on the fly in the form of regular urea from 250 to $300 \mathrm{~kg} / \mathrm{ha}$. However, the rate of nitrogen recovery does not exceed $30 \%$ due to several losses. This justifies the introduction of the deep placement of super-granulated urea (PPU) in order to reduce significant nitrogen losses. This technology tested and validated in a farmers' environment aims to improve yields and reduce rice production costs and raises the impact assessment issue on real income. On a stratified sample of 600 farmers from VFS and the Anambé basin, the Average Treatment Effect method was used with the determinant factors measured by the PROBIT model. The study showed a current technology adoption rate of $29 \%$ overall among producers exposed to technology at a potential rate of $69 \%$. At the zone level, the adoption rate in the Anambé Basin is currently $10 \%$ on a potential rate of $54 \%$, while the valley is registering a higher current rate of $23.3 \%$ on a potential of $70 \%$. These results are justified by the low level of diffusion through the demonstration tests and field visit. It is clear that having formal education, rice-growing experience and being in contact with a development project are key factors in accessing technology. The impact on yield was $917 \mathrm{~kg} / \mathrm{ha}$ statistically significant at $1 \%$ throughout the study. It is $1085 \mathrm{~kg}$ in the valley and $750 \mathrm{~kg}$ in the Anambé. The average effect of the adoption on income is $142923 \mathrm{FCFA}$ per ha with a higher gain of VFS farmers (154 190 FCFA) compared to 130655 FCFA for those of Anambé. The income and yield differential in the valley is justified by experience, training and closer supervision. The large-scale expansion of PPU technology in Senegal can help accelerate the walk towards rice self-sufficiency while offering business opportunities to input suppliers. However, it is recommended that granular and applicators be put in place to accompany the more efficient use of the technology.
\end{abstract}

Keywords: Farmer; Fertilizer; Super-granular; Rice; Income; Yield

Abbreviations: VFS: Senegal River Valley; ATE: Average Treatment Effect; UDP: Deep Urea Placement; FNRAA: National Fund for Agricultural and Agri-Food Research; ATT: Average Treatment Effect on the Treaties

\section{Introduction}
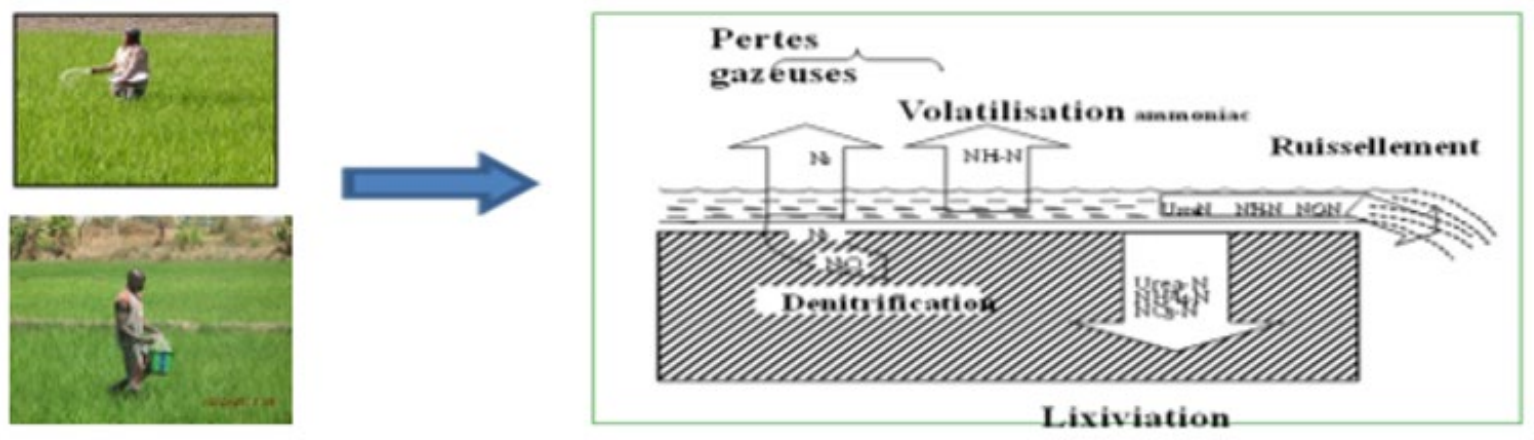

Figure 1: The deep placement of super granulated urea (PPU) technology. 
In the Senegal River Valley and the Anambé Basin where yields are high (averaging 4.5 to $7 \mathrm{t} / \mathrm{ha}$ ), the use of fertilizers is crucial. Nitrogen fertilizers are generally applied in an irrigated system by broadcast application in the form of ordinary urea of 250 to $300 \mathrm{~kg} / \mathrm{ha}$. However, the recovery rate of nitrogen hardly exceeds $30 \%$ for the rice plant [1]. This form of application results in significant losses of nitrogen in the runoff water, groundwater and air, reducing the amount available to the plant while polluting the environment (Figure 1).

Compared to this practice, the deep placement of super granulated urea (PPU) technology is a technique of burying by hand or applicator a super granule of urea fertilizer or "briquette" be tween 4 rice bunches at a depth $7-10 \mathrm{~cm}$ [2]. Thus, urea buried in the soil slowly releases nitrogen to the benefit of plants and reduces losses in water and the atmosphere. It improves the rate of recovery of nitrogen by the plant. The technology showed an average gain of $1105 \mathrm{~kg}$ per ha $(20 \%)$ and an average decrease in variable production costs of $18 \%$, mainly related to a significant $48 \%$ reduction in urea quantities [3]. However, PPU technology is highly dependent on the availability of urea pelletizing machines and applicators. This technology, tested and validated in a farm environment, aims, among other things, to improve rice yields and reduce production costs.

Technology is often seen as paying, however, there is a lack of quantifiable information on the social impact of this technology in the country's overall rice management. Thus, the large-scale expansion of technology proves to be essential, but requires investment, which often leads to the questioning of decision-makers as to their desirability. This poses the problem of assessing the contribution of technology to rice farmers and the global economy. The objective of this study is to evaluate the economic impact of the adoption of technology on rice cultivation in the Senegal River Valley and the Anambé Basin.

\section{Methodology}

\section{Sampling}

With the breadth and heterogeneity of the study area, stratification was done on the basis of a multi-stage reasoned sampling choice. These are steps developed to select basic observation units where representativeness requirements are met. The first stage is devoted to identifying areas and study sites with a reasoned choice based on the knowledge acquired (typology and characterization studies). Thus, in the Senegal River Valley, the delta and the middle valley areas were chosen. The villages of Dagana, Gaya and Bokhol are representative of the Delta, while Dimath, Fanaye, Podor, Donaye, NDieurba and Matam represent the ecology of the Middle Valley. The villages of Awataba, Soutouré, Anambé, Kalégné, Kounkane, Kabendou and Saré Bouty represent the ecology of the Anambé Basin. In the second stage, a random selection was made on the selected sites at the rate of 350 rice growers in the valley and 250 in the Anambé Basin. The size of the sample in each zone is distributed among the villages selected in proportion to their size. After withdrawal during the surveys and data cleaning, the overall sample size of the study is reduced to 546, of which 303 in the valley and 243 in the Anambé basin. A questionnaire aimed at collecting information on dissemination plots of target (technology exposed) and control (non-exposed) farm managers was administered to assess the impact of the adoption of deep placement technology urea (PPU).

\section{Analysis Framework}

The framework for analyzing counterfactual results is used whereby each rice farmer in the population has two potential outcomes: with and without exposure to the technology [4-6]. Thus, the impact and uptake of PPU technology is estimated with the average treatment effect (ATE). Determinants of access are measured by the probit model of exposure. The marginal effects of the probability of exposure were estimated. In concrete terms, let $y_{1}$ be the potential result of a rice farmer when he is exposed to the technology and $\mathrm{y}_{0}$ the potential result when he is not exposed. The adoption outcome can be either adoption status (a 0-1 binary variable) or a measure of adoption intensity such as the total area allocated to new technologies [7]. Then, the treatment effect for a rice grower is measured by the difference between $\mathrm{y}_{\mathrm{i} 1}-\mathrm{y}_{\mathrm{i} 0}$. Thus, the impact of the expected adoption in the exposure population to the new technology is given by the estimated value of $\mathrm{E}\left(\mathrm{y}_{1}-\mathrm{y}_{0}\right)$, which by definition is the average treatment effect, ATE. Unfortunately, we only observe $y_{1}$ for rice farmers exposed to the technology and we cannot estimate the expected value of $y_{1}$.

Let $\mathrm{w}$ be a binary indicator for exposure to new technology, where $\mathrm{w}=1$ represents exposure and $\mathrm{w}=0$ if not. The average impact of adoption in the exposed subpopulation is given by the conditional value $E\left(y_{1} / w=1\right)$, which is by definition the average treatment effect on the treaties (ATT). Since we observe $y_{1}$ for exposed rice farmers.

$$
A T T=E y_{1}=P(w=1) \times A T E 1+(1-P(W=1)) \times E\left(y_{1} / w=0\right)
$$

Where $\mathrm{P}(\mathrm{w}=1)$ is the probability of access to the technology. Thus, once ATE, ATT and the probability of exposure, P ( $\mathrm{w}=$ 1) are estimated, we can obtain from (1) the non-exposure bias $B N E=P(w=1) \times A T T-A T E$; the expected bias using the sample's average adoption rate based on knowledge and access to technology. The selection bias at the level of the PSB population is given by:

$$
P S B=A T E 1-A T E=E\left(y_{1} / w=1\right)-E\left(y_{1}\right)
$$

The average treatment effect (ATE) can be identified using methods that rely on the conditional independence assumption. These methods state that the treatment status $w$ is independent of 
the potential outcomes $\mathrm{y}_{1}$ and $\mathrm{y}_{0}$ conditional on a set of covariates $z$ that determines the exposure $(w)$. ATE estimators using the conditional independence assumption are either based on pure parametric regression, where the co-variables can interact with the treatment status variable to account for heterogeneity, or on an estimation procedure at two stages where the conditional probability of treatment $P(A=1 / X)=P(X)$ (called the propensity score), is estimated in a first step and ATE, ATE1 and ATE0 are estimated in a second step by methods parametric or non-parametric regression. This study uses two different estimators to estimate ATE:

a. Semi-parametric estimator.

b. A parametric method.

\section{Results and Discussion}

\section{Characterization of Production systems in Both Zones}

The level of performance depends primarily on the production objectives. Most logging models in the valley have a goal of both consumption but sale to pay back credits. Thus, with the commercial objective, this cash crop is the object of investment (inputs and provision of mechanized services). The model that comes closest to the commercialization goals requires the highest level of expense. The study shows that the average cost of production of the various types of exploitation of the valley is estimated at 101 FCFA $/ \mathrm{kg}$, of which $10 \%$ of fertilizer cost with a margin of 29 FCFA/ $\mathrm{kg}$. With an average yield level of 6.5/ha, the net margin is 160000 FCFA per ha.

In the Anambé Basin, the study reveals relatively average production levels (a yield of 3.5t/ha). This system induces an estimated production cost of $85 \mathrm{FFCA} / \mathrm{kg}$. The main production costs consist of inputs (99,000 FCFA/ha) including 7\% fertilizer cost and harvest and post-harvest costs $(85,000 \mathrm{FCFA} / \mathrm{ha})$. Thus, the Anambé rice system remains weakly mechanized compared to the Senegal River valley. With the net margin per hectare is estimated at 130,000 FCFA/ha, while the margin is $40 \mathrm{FCFA} / \mathrm{kg}$. The majority of producers have shortcomings in good farming practices. The application of the doses and date of sowing of seeds and the spreading of fertilizers do not follow for the majority, the recommended standards.

\section{Level and form of Use of Fertilizers in Study Areas}

The study showed that the use of fertilizer varies with crops and areas. Fertilizer is widely used in irrigated areas (100\%) and poorly used (39\%) in rainfed rice. In the Anambé zone, the fertilizer used on rice concerns only the developed perimeters of the Basin, while in the valleys around the Basin, fertilizer is used very little (less than 5\%). Manure and other crop residues are more used in these areas. Lack of resources and low levels of yield (not benefiting the profitability of the crop with the use of fertilizers) are the main reasons for non-use of fertilizers. This amply justifies the introduction of PPU technology in order to reduce the costs of fertilizers and to encourage the behavioral change of rice farmers on the consumption of fertilizers.

In terms of formula, NPK fertilizer 18-46-00 is the most applied in the valley (97\%) against 3\% for NPK 923 30. The use of the latter formula providing potassium is rather related the difficult physical access of NPK 18-46-00 recommended on the market during certain times of the year. In the Anambé Basin, bottom fertilizers, NPK 18-46-00 are used by rice growers. NPK is applied after plowing for the majority of rice farmers $(96 \%$ for the river valley and $70 \%$ for those of the Anambé Basin). The average application rate of the valley is $150 \mathrm{~kg} / \mathrm{ha}$ for NPK and $100 \mathrm{~kg} / \mathrm{ha}$ for the Basin all on the fly.

Urea is considered a cover fertilizer that is heavily used in the valley with an average of $300 \mathrm{~kg} / \mathrm{ha}$ in two fractions for the majority of rice farmers (89\%). At the level of the Anambé Basin, the average dose used for urea is $250 \mathrm{~kg} /$ ha with also two fractions. These results led to widely varying levels of yield (an average of $6.5 \mathrm{t} / \mathrm{ha}$ in the river valley with a high coefficient of variation (CV) of 0.44 and $4.5 \mathrm{t} / \mathrm{ha}$ in the Basin with a CV also very high of (0.55) These high levels of coefficient of variation indicate a great variability of the yields with a minimum of $4 \mathrm{t} / \mathrm{ha}$ and maximum of $8 \mathrm{t} /$ ha in the valley. Anambé, the minimum yield is $1 \mathrm{t} / \mathrm{ha}$ (in the valleys with the rain) and the maximum at $5 \mathrm{t} / \mathrm{ha}$.

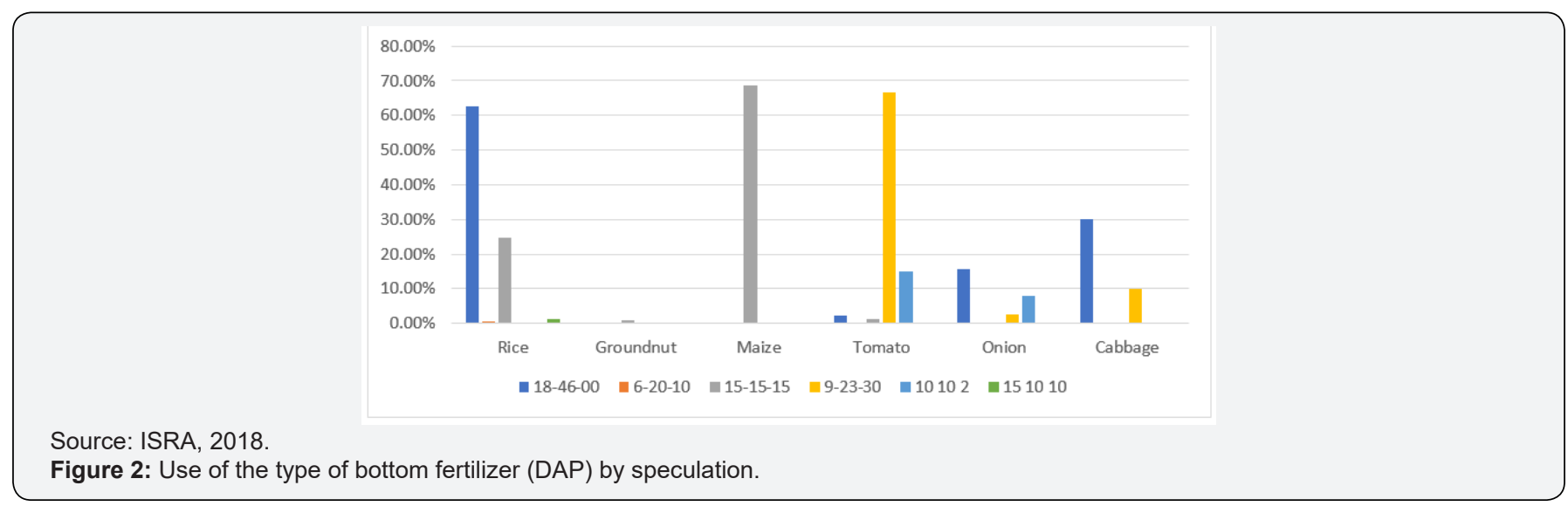


The study showed several types of background fertilizer depending on the crop (Figure 2). Rice uses 18-46-00 for 63\% of producers and $15-15-15$ for $25 \%$ of rice farmers. Maize cultivation also uses $15-15-15$ for $669 \%$ of the producers in the study, while tomato consumes 9-23-30 for the majority of respondents (67\%).

\section{Form utilization of PPU Technology}

The technology is the deep placement of nitrogen in the form of super granular urea (USG) with the use of a suitable applicator. To obtain the USG, it suffices to compact the pearl urea or ordinary urea using a machine called granular. Deep Urea Placement (UDP) technology involves burying a Super Urea Granule (USG) or "bri- quette" between four (4) rice cans transplanted at $20 \mathrm{~cm} \times 20 \mathrm{~cm}$ spacings 7 days after transplanting. on a depth of $7-10 \mathrm{~cm}$. This landfill is done every $40 \mathrm{~cm}$ on direct seeding rice at 2 weeks after sowing. The granules buried in the soil and slowly releasing the nitrogen for the benefit of the plants, reduce the losses in the water and the atmosphere. Indeed, with localization, it results:

a. A high concentration of ammoniacal urea $\mathrm{N}\left(\mathrm{NH}_{4}-\mathrm{N}>\right.$ 3,000ppm).

b. An increase in $\mathrm{pH}(9)$.

c. An inhibition of nitrification (Figure 3).

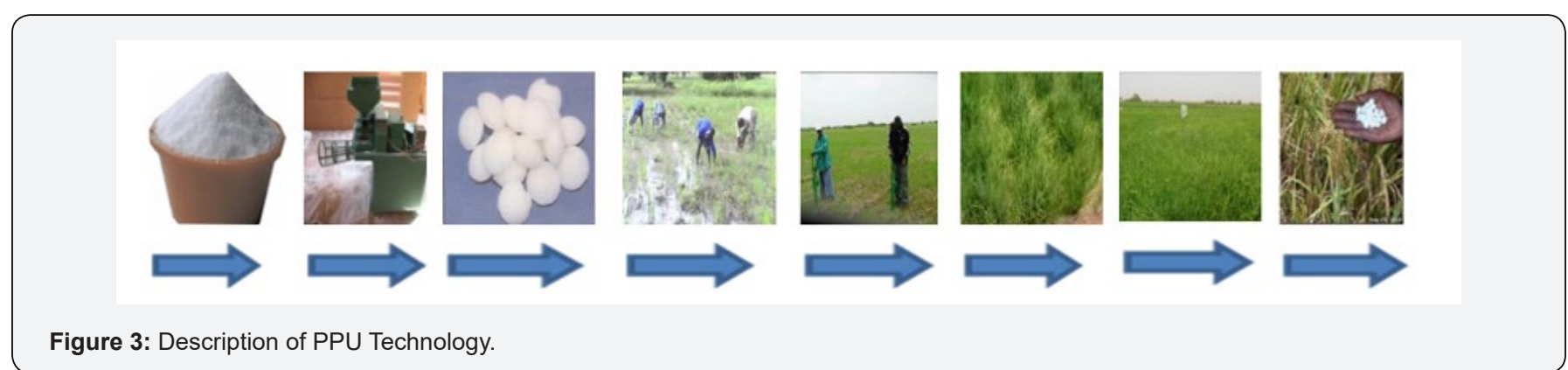

\section{Rate of Adoption of PPU Technology}

Table 1: PPU technology adoption rate and gap across all study areas.

\begin{tabular}{|c|c|c|}
\hline Indicator Adoption & $\begin{array}{c}\text { ATE (Semi- } \\
\text { Parametric Method) }\end{array}$ & ATE (Probit Method) \\
\hline ATE & $0.68(0.082)^{*}$ & $0.69(0.038)^{* * *}$ \\
\hline ATE1 & $0.7(0.137)$ & $0.69(0.03)^{* * *}$ \\
\hline ATE0 & $0.67(0.073)^{*}$ & $0.69(0.038)^{* * *}$ \\
\hline JEA & $0.29(0.056)^{*}$ & $0.29(0.013)^{* * *}$ \\
\hline GAP & $-0.39(0.04)^{* *}$ & $-0.4(0.02)^{* * *}$ \\
\hline PSB & $0.019(0.077)$ & $0.0049(0.017)$ \\
\hline Observation (N) & 546 & \\
\hline Exposed (Ne) & 226 & \\
\hline Adopters (Na) & 157 & \\
\hline
\end{tabular}

Source: ISRA, 2018. NB: Standard Error are in parentheses.

${ }^{* * *}=$ very significant (from 1 to less than $5 \%$ ); ${ }^{* *}=$ significant at the $5 \%$ threshold) and ${ }^{*}=$ slightly significant at the $10 \%$ threshold)

With the estimation of the Tobit effect, the results show that all the estimated parameters are significant at the $1 \%$ level, except for selection bias (PSB) (Table 1). Of the entire sample (546), only $41 \%$ (or 226) were exposed by technology (either by experimentation or by visits and training). Of these presentations only $29 \%$ (i.e., 157 rice growers from both areas) adopted the technology. As a result, the current rate of technology adoption (JEA) is $29 \%$ (Table 1). However, the potential adoption rate (ATE) is 69\%. This means that if the entire population had access to technology, then the current adoption rates in 2018 would be $69 \%$. This induces a statistically significant $40.7 \%$ negative gap provided through non-exposure (GAP). Thus, these different results show that it is still possible to increase the rate of adoption in the study area. Selection bias (PSB) shows that access to technology is dependent on the adoption of new technology, but this parameter is not statistically significant. These results corroborate those found by Diagne [7], and Dibba [8] who revealed that access or exposure is crucial in the adoption of new technologies. With the semi-parametric estimation method, the same results are observed on all the indicators except selection bias (PSB). However, the results are not statically significant as is the case with the Probit method.

Table 2: Adoption Rate and Deviation of PPU Technology by Basin.

\begin{tabular}{|c|c|c|}
\hline & Anambé Basin & Senegal River Valley \\
\hline Adoption & $\begin{array}{c}\text { Estimation Probit } \\
\text { (PPU) }\end{array}$ & $\begin{array}{c}\text { Estimation Probit } \\
\text { (PPU) }\end{array}$ \\
\hline ATE & $0.541(0.05) * *$ & $0.700(0.037) * *$ \\
\hline ATE1 & $0.432(0.038)^{* * *}$ & $0.669(0.035)^{* *}$ \\
\hline ATE0 & $0.574(0.059)^{* *}$ & $0.717(0.043) * *$ \\
\hline JEA & $0.101(0.009)^{* * *}$ & $0.236(0.012)^{* * *}$ \\
\hline GAP & $-0.440(0.0045) * * *$ & $-0.463(0.028) * * *$ \\
\hline PSB & $-0.108(0.042)^{* *}$ & $-0.031(0.021)$ \\
\hline $\begin{array}{c}\text { Number of } \\
\text { Observations }(\mathrm{N})\end{array}$ & 243 & 303 \\
\hline Exposed $(\mathrm{Ne})$ & 57 & 107 \\
\hline Adopters (Na) & 25 & 72 \\
\hline
\end{tabular}

Source: ISRA, 2018. NB: Standard Error are in parentheses.

${ }^{* * *}=$ very significant (from 1 to less than $5 \%$ ); ${ }^{* *}=$ significant at the $5 \%$ threshold) and * $=$ slightly significant at the $10 \%$ threshold)

At the zone scale, the adoption rate of technology in the Anambé Basin is currently $10 \%$ at a time when the potential rate is es- 
timated at 54\% (Table 2). This means that if the entire population of the Anambé Basin were exposed to the technology, more than $54 \%$ of the rice farmers would be adopters. This induces a current gap of $-43.9 \%$ which can be explained by the fact that the diffusion of technology is relatively weak in the Anambé basin where the producers use less fertilizer (section 3.2.). Second, the use of new technology is not widespread enough. It was limited to demonstration trials and field visits. Circulation conditions around a research program remain low due to insufficient means to produce enough recommended granules and to reach a larger mass of the population. In fact, only $24 \%$ of the study population is exposed to technology. Access to the raw material, granular urea is only circumscribed to the demonstration plots. There is not even a granular machine in the area. Nevertheless, the research and development project distribute these forms of fertilizer to the targeted producers in addition to the applicators.

In the Senegal River Valley, PPU technology, on the other hand, has a current adoption rate of $23.62 \%$ while the potential adoption rate is $70 \%$ if rice farmers were exposed to the technology. Only $35 \%$ of the surveyed population is exposed to the technology. This generates a gap to fill of $-46.3 \%$ (Table 2). Thus, technology is better appreciated in the valley than in the Anambé Basin.
This is justified by the need for higher fertilizer in the valley where production is more than two-thirds commercial. Then, this is the first area where this technology has been experimented, even inducing an association of users of super-granular urea. In addition, there are two granular machines introduced by IFDC and SAED in the valley and none in the basin. Therefore, the existence of super-granular fertilizers and applicators on the market within the grower's reach is a major challenge in the sustainable use of technology in place of ordinary fertilizers.

\section{Determinants of Access to Technology}

Table 3 presents the results. It appears that the fact of having a formal education as well as the area planted with rice are determining factors in the access to the technology with a threshold of significance of $1 \%$. So, the more educated the person is, the greater the probability of exposure. The marginal effect indicates this factor could improve the probability of exposure by $15 \%$. Fall [9] showed that young producers in the Senegal River Valley, with a higher level of education than formerly known in the rural world, are open to technological innovations but remain very critical. Also, the larger the area planted with rice, the greater the chance for the producer to be exposed to PPU technology. This factor would increase the chance of exposure to technology by $11 \%$.

Table 3: Determinants of access to technology in the surveyed areas.

\begin{tabular}{|c|c|c|c|}
\hline Variables & Estimated Coefficients & Std. Err. & Marginal Effect \\
\hline Household Size & 0.012 & 0.015 & 0.003 \\
\hline Number of Active in $\mathrm{HH}$ & $0.05^{* *}$ & 0.019 & $0.02^{* *}$ \\
\hline Producer Age & 0.006 & 0.007 & 0.004 \\
\hline Marital Status (Married) & 0.3 & 0.29 & 0.06 \\
\hline Alphabetized & 0.19 & 0.23 & 0.079 \\
\hline Formal Training Level & $0.47^{* * *}$ & 0.14 & $0.15^{* * *}$ \\
\hline Agriculture as Principal Activity & 0.27 & 0.38 & 0.1 \\
\hline Technical Rice Training & $0.43^{* *}$ & 0.2 & $0.19^{* *}$ \\
\hline $\begin{array}{l}\text { Rice Cropping Experiences } \\
\text { (Number of Years) }\end{array}$ & -0.003 & -0.003 & -0.002 \\
\hline Rice Cultivated Area in 2018 & $0.276^{* * *}$ & 0.29 & $0.11^{* * *}$ \\
\hline $\begin{array}{c}\text { Total Cultivated Land Area } \\
\text { Available }\end{array}$ & 0.036 & 0.031 & 0.013 \\
\hline Head of Household Rice Cultivator & -0.136 & 0.19 & -0.03 \\
\hline $\begin{array}{l}\text { Secondary Activity other than } \\
\text { Agriculture }\end{array}$ & 0.77 & 0.58 & 0.29 \\
\hline Be in Contact with Project & $0.35^{* *}$ & 0.17 & $0.17^{* *}$ \\
\hline Number of Small Equipment & -0.011 & 0.032 & -0.008 \\
\hline Number of Large Materials & -0.09 & 0.071 & -0.029 \\
\hline Access to Information & 0.35 & 0.23 & $0.11^{*}$ \\
\hline Constant & -1.09 & & \\
\hline Number of Observations & 546 & & \\
\hline Log Likelihood & -190.15 & & \\
\hline Pseudo R2 & 0.162 & & \\
\hline
\end{tabular}

Source: ISRA, 2018. NB: ${ }^{* *}$ significant at the $1 \%$ threshold: ${ }^{* *}$ significant at the $5 \%$ threshold and ${ }^{*}$ significant at $10 \%$. 
In the fertilizer technology introduction programs, the technical partners in research and development have generally targeted the largest producers who plant more rice in the area. Indeed, the technology is more worn by these producers because they are the most interested in technologies that would reduce their production costs while increasing their level of performance.

In addition, training in rice cultivation and being in contact with development project are decisive factors for access to technology and statistically significant at the 5\% level. The training enhances the producer's expertise and remains a considerable asset for easy access to technology. It contributes to better access to information on technological innovations and their better understanding. This predisposes producers to be better able to access the technology. The impact of the training is explained by the fact that the technology of the application of super-granular fertilizers requires a certain technicality (burial, understanding of the mechanisms of loss of nitrogen on the fly, etc.) which makes Training is essential to benefit from the benefits of technology. Thus, trained producers have more information on new technologies. The marginal effect of the Tobit model of regression reveals that rice training could improve the probability of exposure by $19 \%$. Nevertheless, access to information is significant at the $10 \%$ threshold.

In addition, the dissemination of PPU technology has been driven by several research and development projects including IFDC, ISRA and SAED. The purpose of these projects was to popularize technology as an alternative to reducing fertilizer costs and increasing yields. In addition to the distribution of granular fertilizers and the applicator, the projects facilitated the introduction of tested and validated technology in irrigated areas. The results indicate that being in contact with a development project would increase the chance of being exposed to $17 \%$ statistically significant technology at the $5 \%$ threshold.

The results show that the number of household assets is also positively correlated with access to technology. As the number of assets is important in the household, as the household has chances of membership in farmers' organizations where generally the choice of producers operates on carriers of testing or exposure technologies. Thus, the farm manager is more likely to be exposed to the technology. The marginal effect reveals that the number of assets could improve the probability of exposure by $2 \%$ with a significant difference at the $5 \%$ threshold. Indeed, the availability of active labor is very important for this technology with the burial of granulated urea in $40 \mathrm{~cm}$ deep. Moreover, this arduousness limits the expansion of its use.

\section{Determinants of the Probability of Adopting PPU Technology}

Table 4 presents the determinants of adoption of the technology and the coefficients of the classical adoption and joint exposure model. The results of the probit ATE or parametric model concern only the sub-population exposed to the technology introduced in the framework of ISRA's project in partnership with ANCAR and SAED and financed by the National Fund for Agricultural and AgriFood Research (FNRAA). This is compared with the entire population estimates of the classic probit model of adoption and joint exposure. These two models are compared to explain the determinants of adoption.

Table 4: Determinants of adoption of pellet fertilizer placement technology.

\begin{tabular}{|c|c|c|c|c|}
\hline \multirow{2}{*}{ Variables } & Parametric Model & Classical Model & Parametric Model & Classical Model \\
\hline & \multicolumn{2}{|c|}{ Estimated Coefficients } & \multicolumn{2}{|c|}{ Marginal Effect } \\
\hline Household Size & 0.06 & 0.04 & 0.02 & 0.016 \\
\hline Number of Active per $\mathrm{HH}$ & 0.02 & 0.04 & 0.007 & 0.02 \\
\hline Producer Age & $-0.031^{*}$ & -0.02 & $-0.01^{*}$ & -0.002 \\
\hline Alphabetized & -0.57 & 0.14 & -0.25 & 0.087 \\
\hline Formal Training Level & -0.43 & 0.19 & -0.06 & $0.14^{*}$ \\
\hline Agriculture as Principal Activity & -0.45 & -0.18 & -0.07 & -0.002 \\
\hline Technical Rice Training & 0.41 & $0.41^{*}$ & 0.107 & $0.15^{* *}$ \\
\hline Rice Cropping Experiences & $0.031^{*}$ & $0.009 *$ & $0.011^{* *}$ & $0.005^{*}$ \\
\hline Cultivated Rice Area in 2018 & 0.22 & $0.36^{* *}$ & 0.07 & $0.12^{* * *}$ \\
\hline Total Cultivated Land Available & 0.03 & 0.05 & 0.007 & 0.013 \\
\hline Household Head Rice Cultivator & 0.85 & -0.008 & 0.27 & 0.02 \\
\hline Having Secondary Activity & $2.15^{*}$ & -0.64 & $0.28^{*}$ & -0.09 \\
\hline Contact with Project & 0.6 & 0.23 & 0.16 & 0.081 \\
\hline Number of Small Equipment & $0.32^{* * *}$ & 0.09 & $0.09^{* * *}$ & 0.013 \\
\hline Number of Big Equipment & -0.06 & -0.042 & -0.013 & -0.011 \\
\hline Listening Radio & $-1.3^{*}$ & $-0.62^{* *}$ & $-0.25^{* * *}$ & $-0.12^{* *}$ \\
\hline
\end{tabular}

Source: ISRA, 2018. NB: *** significant at the $1 \%$ threshold: ${ }^{* *}$ significant at the $5 \%$ threshold and * significant at $10 \%$. 
In the parametric model, the acquisition of agricultural equipment among the population exposed to the technology is a very significant determining factor at the $1 \%$ level (Table 4). The marginal effect shows that the acquisition of small equipment improves the probability of adoption of the technology by $9 \%$. This is understandable as small equipment such as the applicator for burying the granules is essential for the adoption of the deep placement of super-granular urea technology.

In the factors determining the adoption of technology, the number of years of experience in rice practices and the exercise of a secondary activity, a source of complementary income facilitating access to technology support tools (applicator, granular or granular fertilizers). The number of years of experience is a significant determinant at the $5 \%$ threshold, helping to improve the probability of adoption by $11 \%$. Although not very significant (threshold of $10 \%$ ), the exercise of a secondary activity would contribute to a $28 \%$ improvement in the probability of adoption of the technology. These different determining factors confirm the results of the authors Shulzt [10], Phillips [11] and Fall [12], which highlight the experience and availability of resources as preponderant factors in the adoption of new technologies. The pursuit of secondary activities generates additional revenues that can be used to finance the additional costs associated with the adoption of technologies. In the parametric model, the age of the producer negatively influences the adoption at the $10 \%$ threshold. Indeed, the adoption of PPU technology requires a burial of granular fertilizers according to a respect of the technical routes which can cause heavy work that people of a certain age cannot do.

The classical model (whole sample) shows that the size of the rice area and being trained in rice cultivation are decisive factors in the adoption of the technology at the $1 \%$ and $5 \%$ threshold, respectively. The marginal effects show that these different variables improve the probability of adoption by $12 \%$ and $15 \%$ respectively. Similarly, the number of years of experience in rice cultivation would generally contribute to improving the probability of adoption by less than $1 \%$.

The common determinant of both models is the method of diffusion of the technology. Indeed, the results show that in both models listening to the radio has a negative influence on the prob- ability of adoption of the technology. The marginal effect shows that this factor decreases the probability of adoption by $25 \%$ and $12 \%$ respectively for the model of the subpopulation exposed to the technology and that of the overall sample. In reality, this situation is justified by the fact that this channel of diffusion is not used in the country for the popularization of the improved technologies and even less that of the placement of the super-granulated urea.

The decisive factors in the adoption of PPU technology are the acquisition of small equipment (applicator) and to a lesser extent the exercise of a secondary activity and experience. Similarly, the characteristic of the technology requiring a physical capacity (burial of the granules at depth of $40 \mathrm{~cm}$ ) induces the consideration of the age in the determining factors to the adoption of the technology with a negative correlation. On the other hand, it is shown that the formation and size of area planted are potential technology adoption factors. For widespread access to technology, it is important to consider these different elements to maximize the probability of adoption [13-16].

\section{Impact of the use of PPU technology on producers income}

Table 5 shows the average returns and incomes between adopters and non-adopters of the technology. A difference of $917 \mathrm{~kg} / \mathrm{ha}$ is statistically significant at $1 \%$ between the two groups throughout the study. On a scale, this difference is 1, $085 \mathrm{t}$ in the valley and $750 \mathrm{~kg}$ in the Anambé basin in favor of users of the technology with a relatively significant significance at the $1 \%$ threshold. This shows a comparatively higher advantage for adopters. In terms of income, the finding is the same. Adopters have a significant differential at the $1 \%$ level of 114,000 FCFA/ha for the entire study. This varies from CFAF 135,600 per hectare between adopters and non-adopters in the valley, while this differential is CFAF 93,750 per hectare in the basin, still in favor of adopters. Valley producers have higher incomes driven by higher levels of yield. For the presentation population, valley producers are fortunate to be exposed to technology before those in the Anambé basin. Thus, the results show a greater significant difference for adopters, both by performance and by income. However, this descriptive analysis does not accurately estimate the impact of technology as a result of adoption. The econometric analysis of adoption will confirm or not these descriptive trends.

Table 5: Average rice yields and incomes of adopters and non-adopters.

\begin{tabular}{|c|c|c|c|c|}
\hline Variables & Zone & Adopters & Non-Adopters & Differential Average \\
\hline \multirow{2}{*}{ Yield (kg/ha) } & Overall & $5,507.5(91.6)$ & $4590(33.3)$ & $-917.5(77.2)^{* * *}$ \\
\cline { 2 - 5 } & Valley & $6,875(115.5)$ & $5790(47.6)$ & $-1085(98.65)^{* * *}$ \\
\hline \multirow{3}{*}{ Rice Income (FCFA) } & Anambé & $4140(82.2)$ & $3,390(29.33)$ & $-750(66.7)^{* *}$ \\
\cline { 2 - 5 } & Overall & $688,437.5(139,781.5)$ & $573,750(41,855.3)$ & $-114,687.50(23,256.8)^{* * *}$ \\
\cline { 2 - 5 } & Valley & $859,375(251,829)$ & $723,750(72,754)$ & $-135,625(43,594.1)^{* * *}$ \\
\hline
\end{tabular}

Source: ISRA, 2018. 
The analysis of the impact of the use of PPU technology on income is presented in Table 6 with three estimation methods. The effect of adoption on income is positive and statistically significant at the $1 \%$ level. The estimation based on OLS gives an average effect of 142,923 FCFA in the population of potential adopters with a higher gain of rice farmers in the Senegal River Valley (154 190 FCFA) against 130656 FCFA for those of the Anambé basin. The yield differential noted in the two zones is a determining factor.
These high levels of performance are also driven by experience, training and closer supervision in the valley. The valley has also benefited from several development projects, including those introducing PPU technology. In addition, the emphasis on the use of the technology also depends on the availability of the granular that exists only in the valley. All of these factors justify the differential impact of rice farmers in the valley.

Table 6: Impact of the adoption of the deep placement of super-granular urea on income.

\begin{tabular}{|c|c|c|c|}
\hline & Overall & Valley & Anambé \\
\hline Number of Observation (N) & 546 & 303 & 243 \\
\hline $\begin{array}{l}\text { Number Farmers Exposed to PPU } \\
\text { Technology (Ne) }\end{array}$ & 164 & 107 & 57 \\
\hline Number of Adopters (Na) & 97 & 72 & 25 \\
\hline \multicolumn{4}{|l|}{ OSL Estimates (LARF) } \\
\hline $\begin{array}{l}\text { Average Impact in the } \\
\text { Subpopulation of Potentials } \\
\text { Adopters (LATE) }\end{array}$ & $700848(142923)^{* * *}$ & $819239(154190)^{* * *}$ & $560102(130655.8)^{* * *}$ \\
\hline \multicolumn{4}{|c|}{ "Inverse Propensity Score Weighting" Estimates } \\
\hline ATE & $408534(139756)^{* * *}$ & & \\
\hline ATE1 & $437788(147312)^{* * *}$ & & \\
\hline ATE0 & $396754(136241)^{* * *}$ & & \\
\hline PSB & $29254(19065)$ & & \\
\hline \multicolumn{4}{|c|}{ Least of Squares Estimates } \\
\hline ATE & $457446(135458)^{* * *}$ & & \\
\hline ATE1 & $461400(143301)^{* * *}$ & & \\
\hline ATE0 & $447627(133208)^{* * *}$ & & \\
\hline ATE1 & 9817 & & \\
\hline
\end{tabular}

Source: ISRA, 2018. NB: ATE: Average treatment effect for overall observation or potential adoption rate; ATE1: average treatment effect on exposed population); ATE0: Average treatment effect on the unexposed population.

The propensity score method gives a positive effect on the entire population with an income impact of CFAF 140,000 while the exposed sub-population produces an impact gain of more than CFAF 147,000, significant at the threshold of $1 \%$ (Table 6). The unexposed subpopulation has an impact of 136,000 FCFA. Thus, access to technology improves on average $9 \%$ of the income of producers. The least squares estimate also shows a positive effect with the use of the technology. Rice farmers exposed to the technology still have an income gain of more than 143,000 FCFA, while the impact on the whole and the unexposed are respectively 135,000 and 133,000 FCFA. The marginal effect of using technology for rice farmers in the valley varies between $09 \%$ and $21 \%$ on their income level according to the methods. Thus, these three methods have shown the positive impact of the use of PPU technology on income. This is justified by the agronomic effect of the technology on the improvement of yields, which varies between more than $750 \mathrm{~kg} /$ ha in the Anambé basin and more than one ton/ ha in the Senegal river valley. The technology also makes it possible to reduce production costs at the same time by reducing the consumption of fertilizers. Indeed, the impact is associated with its efficiency because inducing a third (one bag out of three per hectare) consumption of urea. All of these assets make access to technology an important factor in increasing their income and productivity on rice. However, the pulse factors of the technology remain access to granulators and applicators.

The impact of the use of technology in the Anambe Basin depends very much on its level of diffusion. These conditions show the importance of valuing the use of the deep placement of super-granular urea. In the Anambé Basin, the diffusion rate is relatively low because access conditions are difficult. There is no grain needed to process ordinary fertilizers and few applicators are distributed to producers. Access must be made to the facilitation of these tools to improve the level of access and use of this technology. Thus, the revival of the rice sector in this area will necessarily go to these new technologies because the current average yield is $4.5 \mathrm{t} / \mathrm{ha}$ while it is $6.5 \mathrm{t} / \mathrm{ha}$ in the valley. These performance levels predispose this area to maximize access to this technology and gain productivity gains. 


\section{Conclusion and Outlook}

In large parcels of rice scattered in direct seeding (on the fly), the effective participation in the technical evaluation brings a new know-how transforming the peasants into potential agents of extension. PPU technology provides a paddy yield of between 750 and $1050 \mathrm{~kg}$ per hectare depending on the areas of production of the adopters compared to non-adopters. Income improves from $9 \%$ to $21 \%$ of the effect induced by the use of technology. With the PPU, higher profitability is noted with a reduction in the unit cost of production and an increase in the unit margin. The significant reduction of 48 to $50 \%$ in the amount of urea used per hectare with PPU technology leads to a reduction in the pollution of groundwater, rivers and the atmosphere.

The adoption of PPU technology by the producers is the guarantee of the improvement of rice growing. The development and promotion of rice cultivation in the Anambé Valley and the Anambé River Basin necessarily involves the promotion of the deep placement technology of super-granular urea. The number of years of experience in rice practices, the exercise of a secondary activity and the existence of small equipment are proven to be decisive factors in the adoption of the technology. The impact of the use of this technology is on average 9 to $21 \%$ increase in revenue. If the impact of the use is highly high, the access remains limited by the availability of the granulator which produces this super-granulated urea and the application machine which is the applicator. The results showed that diffusion conditions around a research program remain low due to insufficient means to produce enough recommended granules.

The results of this study provide an experimental framework for thinking about appropriate dissemination methods and the need for private sector involvement. The state can press the introduction of granular, while trained local artisans are able to produce the applicators. To establish the conditions for sustaining positive gains from the use of technology, the dissemination mechanism must be revisited by involving the private sector in the supply of granular or granular material to adapt to the appropriate needs of producers. The large-scale expansion of UPP technology in large irrigated rice-growing areas in Senegal can help accelerate the march toward rice self-sufficiency while providing business opportunities for the input and economic suppliers of rice. foreign exchange on import bills for rice and urea for the Senegalese state.

\section{Acknowledgement}

I would like to thank FNRAA (National research and extension fund) which finances this project. Thanks also Dr Mamadou Ndiaye, agronomist ISRA Saint-Louis for his leading work. Thanks to ISRA researchers who contribute in terms of advice and observations. Thanks to my assistant team: Selle Cisse Diatta, Pape Makhoudia Mbengue and Talla Tall.

\section{References}

1. Ndiaye M, Fall AA (2015) Fabrication de granuleuses et d'applicateurs de granules pour la diffusion de la technologie du placement profond de l'urée super granulée en riziculture irriguée dans la vallée du fleuve Sénégal et le bassin de l'Anambé, Rapport d'activité du projet ISRA/ FNRAA. p. 43.

2. IFDC/ISRA (2012) Introduction de la technologie du placement de l'urée super-granulé en riziculture dans la vallée du fleuve, projet de recherches ISRA/IFDC. p. 25.

3. (2015) IDEM Annual Reports. p. 31

4. Imbens G, Wooldrige JM (2009) Recent Developments in the Econometric of Program Evaluation. Journal of Econometric Literature 47(1): 5-86.

5. Heckman J (1996) Identification of causal effects using Instrumental Variables: Comments. Journal of the American Statistical Association 91(434): 459-462.

6. Rosenbaum PR, Rubin DB (1983) The central role of the propensity score in observational studies for causal effects. Biometrika 70(1): 4155.

7. Diagne A (2006) Diffusion and adoption of NERICA rice varieties in Côte d'Ivoire. The Developing Economics 44(2): 208-231.

8. Dibba L (2010) Estimates of NERICA adoption rates and impact on productivity and poverty of the small-scale rice farmers in the Gambia. Thesis submitted to the Faculty of Agriculture, Department of Agricultural Economics, Agri-business and Extension in partial fulfillment of the requirements for the degree of Master of Philosophy in Agricultural Economics, Ghana, pp. 162.

9. Fall AA (2015) Synthèse des études sur l'état des lieux chaîne de valeurs riz au Sénégal. Rapport -VECO Dakar Sénégal. p. 34.

10. Shulzt (1964) Transforming traditional agriculture. University of Chicago Press, Chicago, USA, pp. 212.

11. Phillips J, Groom B (2008) NERICAs: Leading the African Green Revolution? A comparative econometric study of the barriers to adoption of New Rice Crops (NERICAs) in West Africa. University of London, London, UK, p. 74.

12. Fall AA (2008) Impact du crédit sur le revenu des riziculteurs de la Vallée du Fleuve Sénégal. Thèse de Doctorat de troisième Cycle, Ecole Nationale d'Agronomie de Montpellier, Université de Montpellier, France, pp. 341.

13. Diagne A, Demont M (2007) Taking a New look at Empirical Models of Adoption: Average Treatment Effect estimation of Adoption rate and its Determinants. Agricultural Economics 37(2-3): 201-210.

14. Diagne A (2011) Quelles perspectives pour un marché régional du riz? Vers une politique commercial régionale conforme aux objectifs de développement et de sécurité alimentaire. Quels impacts pour l'agriculture malienne? p. 31.

15. Dontsop-Nguezet PM, Diagne A, Okoruwa VO, Ojehomon V (2011) Impact of Improved Rice Technology (NERICA varieties) on Income and Poverty among Rice Farming Household in Nigeria: A Local Average Treatment Effect (LATE) Approach. Quarterly Journal of International Agriculture 50(3): 267-291.

16. Sarr Nd SD (2017) Impact de l'adoption des variétés améliorées de riz sur l'autonomisation des femmes, la productivité et le revenu des ménages dans la région de Fatick, Thèse de Doctorat Unique, UFR Sciences économiques Université Gaston Berger, Saint-Louis, Sénégal, Mars. pp. 168. 


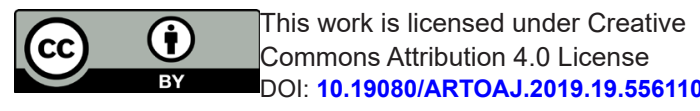

Your next submission with Juniper Publishers
will reach you the below assets
- Quality Editorial service
- Swift Peer Review
- Reprints availability
- E-prints Service
- Manuscript Podcast for convenient understanding
- Global attainment for your research
- Manuscript accessibility in different formats
( Pdf, E-pub, Full Text, Audio)
- Unceasing customer service
Track the below URL for one-step submission
https://juniperpublishers.com/online-submission.php

